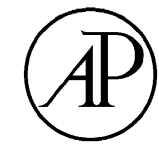

ACADEMIC PRESS
Available online at www.sciencedirect.com

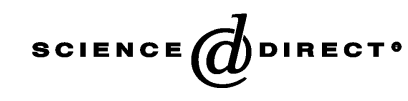

\title{
Trade liberalization, corruption, and environmental policy formation: theory and evidence
}

\author{
Richard Damania, ${ }^{a}$ Per G. Fredriksson, ${ }^{\mathrm{b}}$ and John A. List ${ }^{\mathrm{c}, *}$ \\ ${ }^{\text {a }}$ School of Economics, University of Adelaide, Adelaide, South Australia 5005, Australia \\ ${ }^{\mathrm{b}}$ Department of Economics, Southern Methodist University, Dallas, TX 75275-0496, USA \\ ${ }^{\mathrm{c}}$ The University of Maryland, AREC, 2200 Symons Hall, College Park, MD 20742-5535, USA
}

Received 17 November 2000; revised 5 April 2002

\begin{abstract}
This study explores the linkages between trade policy, corruption, and environmental policy. We begin by presenting a theoretical model that produces several testable predictions, including: (i) the effect of trade liberalization on the stringency of environmental policy depends on the level of corruption; and (ii) corruption reduces environmental policy stringency. Using panel data from a mix of developed and developing countries from 1982 to 1992, we find evidence that supports these conjectures. We view these results as representing an attempt at understanding the myriad of complex relationships that exist in an open economy.
\end{abstract}

(C) 2003 Elsevier Science (USA). All rights reserved.

JEL classification: Q28; F18; D78

Keywords: Political economy; Protectionism; Trade and the environment; Pollution tax

\section{Introduction}

Recent attempts to launch the "Millennium Round" of trade talks have again thrust the relationship between trade and the environment to the forefront of policy discussions. The recurring debate is by now familiar: "free traders" argue, for example, that trade openness creates an economic surplus that can be used for environmental protection measures (see, e.g., [52]). Environmentalists fear, amongst other things, that greater economic integration leads to political pressures to reduce the stringency of environmental regulations in order to protect industry and

\footnotetext{
${ }^{*}$ Corresponding author.

E-mail address: jlist@arec.umd.edu (J.A. List).
} 
Table 1

Change in emission limits

\begin{tabular}{llll}
\hline Pollutant & Mexico City & Other critical zones & Rest of the country \\
\hline & & \multicolumn{2}{c}{ 1994-1997 } \\
$\mathrm{SO}_{2}$ & 1.65 & 3.30 & 5.16 \\
$\mathrm{NO}_{x}$ & 0.23 & 0.41 & 0.59 \\
$\mathrm{PM}$ & 0.05 & 0.25 & 0.39 \\
& & \multicolumn{2}{|}{} \\
$\mathrm{SO}_{2}$ & 1.13 & \multicolumn{2}{c}{ Beginning of 1998} \\
$\mathrm{NO}_{x}$ & 0.16 & 2.26 & 4.53 \\
$\mathrm{PM}$ & 0.04 & 0.16 & 0.55 \\
& & 0.19 & 0.27 \\
\hline
\end{tabular}

Source: CEC [13, p. 345].

employment. ${ }^{1}$ Given the entrenched positions of both sides, further progress in multilateral trade negotiations depends critically on the ability to put this issue to rest. Such progress appears particularly important since empirical evidence suggests that economy-wide growth rates hinge crucially on the openness to trade (see, e.g., [3,24,26,33]).

In this paper, we focus on two major issues that may eventually lead to a resolution of this debate. First, we provide insights into the relationship between trade policy and environmental protection. Table 1 shows how emissions limits have changed in Mexico subsequent to implementation of the North American Free Trade Agreement. The data suggest that emissions standards have become tighter for the three pollutants reported. Of course, without a proper counterfactual this evidence is purely anecdotal. In an attempt to provide evidence that is beyond anecdotes, we examine if trade liberalization is correlated with the stringency of environmental policies. There is a growing literature on the relationship between trade and environmental policy formation. Related theoretical work includes that of Hillman and Ursprung [37] who study the interaction between environmental preferences and trade policy in a model of political competition. They show that the resulting trade policy depends on the nature of the externality, and whether the environmentalists' preferences are defined over the global or only the domestic environment. Leidy and Hoekman [41] explore the effect of the degree of inefficiency of environmental instruments on trade policy determination, and find that polluting industries prefer inefficient environmental policy instruments because they increase the level of trade barriers.

In a related line of research, Copeland [17] explores the welfare effects of trade and environmental policy reforms, also incorporating the case of international factor mobility. Copeland and Taylor [18] analyze the strategic interaction between rich and poor countries in the move from autarky to free trade, allowing for income-induced environmental policy responses. Schleich [49] studies environmental and trade policy selection when both consumption and production involves environmental damages. Extending the received literature, Fredriksson [28] finds that in a perfectly competitive sector, trade liberalization reduces (increases) both

\footnotetext{
${ }^{1}$ See, for example, The Economist, October 9, 1999, p. 17.
} 
industry and environmental lobby groups' incentive to influence environmental policy if the country has a comparative disadvantage (advantage) in the polluting sector. Thus, the final policy effect depends on the relative shifts in political pressures. In a related study, Bommer and Schulze [10] argue that environmental policy is tightened by trade liberalization if the export sector is relatively pollution-intensive, but will be relaxed if the import competing sector is pollutionintensive. $^{2}$

Our attention focuses on the political economy effects of trade liberalization; for example, whether lobbying incentives on environmental issues shift as a result of trade reform. ${ }^{3}$ This focus appears appropriate, as political economy pressures have been found to be important determinants of environmental policy in the US (see, e.g., [12,19,34,45]).

Our second major line of inquiry investigates whether governmental corruption is associated with environmental policies (in a related sense, see $[1,2,43]$ ). In many countries, corruption may play an important role in policy determination, a prospect that has hitherto been relatively ignored in the literature. ${ }^{4}$ We also explore whether these two individual effects have a joint influence on environmental policy-making. Moreover, we investigate the joint effect of demand for environmental quality and corruption on environmental policy. Although this literature is expanding rapidly, the interaction between trade, governmental corruption, and environmental policies has yet to be explored.

To provide structure to our analysis, we present a three-stage common agency model that represents an extension to [9,31]. ${ }^{5}$ Besides providing intuition into the determination of a pollution tax in a protected sector within a framework incorporating political corruption, the model yields several clear predictions. First, the effect of trade liberalization depends on the level of corruption, and whether the polluting sector is import-competing or exporting. Given that trade policy is protective (i.e., an import tariff or export subsidy is used), trade liberalization leads to an increase (decrease) in the pollution tax if the level of government corruption is high (low). If, on the other hand, trade policy is anti-protective (i.e., an import subsidy or export tax is used), trade liberalization results in an increase (decrease) in the pollution tax when the degree of

\footnotetext{
${ }^{2}$ Rauscher [46] provides a model of an open economy where the polluting export sector is found to have ambiguous lobbying incentives.

${ }^{3}$ Related empirical inquiries include Fredriksson and Gaston [29] who investigate empirically the "regulatory chill" hypothesis: whether openness to trade affects the propensity for governments to undertake environmental policy. They find no evidence that more open countries were less prone to cooperate on the global climate change issue. There is also some evidence of the effect of trade liberalization on environmental quality. Dean [23] finds that in China, increased openness to trade has induced greater environmental damage. This is due to China's specialization in polluting sectors. However, increased income levels (due to more open trade) have in turn had a negative effect on emissions growth, reducing pollution levels. Hettige et al. [36], Grossman and Krueger [32], and Antweiler et al. [5] find evidence that more open countries tend to have lower pollution levels. Neither of the above empirical papers discusses corruption and its effect on environmental regulation.

${ }^{4}$ Exceptions are López and Mitra [42], who investigate (theoretically) the effect of corruption and rent-seeking on the relationship between income and pollution levels, and Fredriksson and Svensson [30] who explore the effects of corruption and political instability on environmental policy. They do not explicitly study trade and environmental policies, however.

${ }^{5}$ Aidt [4], Schleich [49], Damania [20], and Eliste and Fredriksson [27] have previously adopted this model to environmental policy formation in sectors with perfect competition. Following Schulze and Ursprung [50], we take the view that the model by Grossman and Helpman [31] closely characterizes a form of high-level corruption. Building on the same model, Coate and Morris [11] also refer to the political contribution offered by a lobbying firm as a "bribe".
} 
corruption is low (high). ${ }^{6}$ The intuition is that the level of corruption determines the relative importance of bribery versus social welfare to the government. For example, when trade policy is protective and the level of corruption is high (low), trade liberalization induces a decline in bribery that dominates (is dominated by) second-best welfare considerations.

A second prediction is that a reduction in corruption unambiguously leads to an increase in the pollution tax. Less corruption implies a greater weight on social welfare and thus the pollution tax will deviate to a lesser degree from the Piguovian tax. A third conjecture is that the environmental policy response to an increase in the demand for environmental quality is positive, but disappears as the level of corruption increases. In highly corrupt societies, policy is shaped primarily by bribery, and unorganized groups have little or no influence on environmental policy.

We test our theoretical predictions using panel data from a mix of 48 developing and developed countries. Our regression estimates support the main predictions emerging from our theoretical model. First, the empirical evidence suggests that countries with more open trade policies tend to have stricter environmental regulations, in particular where the level of corruption is high. These results are robust to several alternative measures of trade policies and environmental regulations, and consistent with our theoretical predictions. Alternatively, where the level of corruption is low this effect may be reversed, which is also consistent with the predictions from the model for protected sectors. Second, the level of governmental corruption is related to environmental standards - we find that lower corruption levels are associated with stricter environmental regulations. We find an additional interaction effect between corruption and trade liberalization: distorted trade policies increase the effect of corruption. Thus, the data suggest that a decrease in corruption levels has a greater effect on environmental policy in relatively closed economies. As such, the evidence implies that corruption and protection are complements in the creation of lax environmental policies. Finally, we find only weak evidence in favor of an empirical interaction between the demand for environmental quality (as measured by income) and the level of corruption.

The remainder of our study is organized as follows. Section 2 outlines the structure of the model and summarizes certain properties of the equilibrium. Section 3 presents the predictions. Section 4 specifies the empirical model and discusses the data. Section 5 presents the empirical results, while Section 6 concludes.

\section{The model}

We consider a small open economy with two perfectly competitive sectors. The numeraire sector produces good $z$, and the polluting sector produces good $x$. There are four types of agents in the economy: consumers with and without environmental concerns, producers (factor owners), and the government. There are $N$ consumers, out of which a share $0<\gamma<1$ suffer disutility from pollution, and therefore $(1-\gamma)$ do not. The fraction $\gamma$ is assumed to reflect the demand for environmental quality amongst consumers. All consumers derive income from labor, while

\footnotetext{
${ }^{6}$ Antweiler et al. [5] conclude that the effects of trade openness on pollution emissions depend on a country's comparative advantage. In their model, trade liberalization always increases the pollution tax due to positive income effects. They do not consider effects of corruption, however.
} 
producers earn income from both labor and the ownership of a sector-specific factor. The utility of consumers with environmental concerns is given by

$$
U=z+u(x)-\theta X
$$

whereas consumers without environmental concerns have utility given by

$$
U=z+u(x)
$$

where $z$ and $x$ are consumption of the numeraire good and good $x$, respectively. $\theta X$ is the total damage from pollution where $\theta$ is the per-unit damage function, $X$ is the total domestic output of good $x$, and $u(x)$ is a concave and twice differentiable sub-utility function.

The domestic and world market price of the numeraire good is unity, and that of good $x$ on the domestic market is $P$. Since this utility function implies that the marginal utility of income is unity (given that consumption of good $z$ is positive), the first-order condition yields $\partial u(x) / \partial x=P$. Hence, each consumer's demand for good $x$, denoted by $d(P)$, is the inverse of $\partial u(x) / \partial x$. Thus, consumer surplus from good $x$ may be defined as $C(P)=u(d(P))-P d(P)$.

Trade policies may be of two types in this paper, either "protective" (domestic output expands) or "anti-protective" (domestic output contracts). Trade policy is protective when domestic import competing producers of the polluting good $x$ are protected by an import tariff $\tau \in T \subset R_{+}$, or when exporters of good $x$ enjoy an export subsidy, $s \in S \subset R_{+}$. Trade policy is anti-protective when domestic import competing producers of $x$ encounter an import subsidy (a negative tariff) $\tau \in T \subset R_{-}$, and when exporters of good $x$ face an export tax (a negative subsidy) $s \in S \subset R_{-}$. Our analysis applies to the case where the protected (or anti-protected) sector is polluting in production. Trade policy is assumed determined by multilateral negotiations over which this small country has negligible influence, and thus all domestic actors take the trade policy instrument as exogenous. ${ }^{7}$ We thus abstract from the determination of the tariff rate in this paper. As pointed out by Ederington [25], the success of GATT negotiations in lowering tariff barriers worldwide has resulted in a shift in attention towards the use of domestic policies as secondary trade barriers. ${ }^{8}$

Let $p^{*}$ be the world market price of good $x$; consumers' domestic price is then given by $P=(1+\tau) p^{*}$ if the sector is import-competing, and $P=(1+s) p^{*}$ if it is exporting. Without loss of generality, we focus our discussion below primarily on the case of an import-competing sector, but return to the case of an exporting sector when the difference is of interest.

Since production of good $x$ results in local pollution, the government attempts to control emissions by levying an emissions tax, $t \in T \subset R_{+}$, per unit of pollution. Per-unit damage is a function of the amount of abatement per unit of output, given by $A$, such that $\theta=\theta(A)$. Abatement uses labor input, and $\partial \theta / \partial A<0, \partial^{2} \theta / \partial A^{2}>0$. The amount of abatement is determined

\footnotetext{
${ }^{7}$ This assumption follows [10,28]. Bommer and Schulze argue that opposition emerged only after the NAFTA negotiations had been put on the agenda. Note also that once a government has committed to a trade policy, environmental policy (generally) remains flexible since few pollutants are regulated by international agreements. Moreover, Articles I and II of the GATT require that all tariffs are non-discriminatory (the MFN principle) and the level of tariff protection does not exceed any binding levels that member countries have agreed upon (see also [25]).

${ }^{8}$ Copeland [15,16], Ederington [25] and Conconi and Perroni [14] discuss the formation of multi-dimensional international agreements.
} 
simultaneously with output. Producers of good $x$ therefore receive a net price per unit of output equal to $P^{N}=p^{*}(1+\tau)-t \theta(A)-A$, disregarding labor costs.

Good $z$ is manufactured under constant returns to scale using only labor. The aggregate quantity of consumers' labor $L$ is sufficiently large to ensure a positive supply of this good and hence the wage rate is unity. Good $x$ is produced using labor and a sector-specific input, under constant returns to scale. Rewards to the sector-specific factor are denoted as $\pi\left(P^{N}\right)$. By Hotelling's Lemma, total output of the polluting good is given by $X\left(P^{N}\right)=\partial \pi\left(P^{N}\right) / \partial P^{N}$, where we assume $\partial X\left(P^{N}\right) / \partial P^{N}>0$, and $\partial^{2} X\left(P^{N}\right) / \partial P^{N^{2}}=0$. The FOC with respect to abatement is

$$
\frac{\partial \pi\left(P^{N}\right)}{\partial A}=-X\left(t \frac{\partial \theta}{\partial A}+1\right)=0,
$$

which can be totally differentiated to obtain $d A / d t=-(\partial \theta / \partial A) / t\left(\partial^{2} \theta / \partial A^{2}\right)>0 .{ }^{9}$ Import volume of good $x$ equals

$$
M\left(P^{N}\right)=N d(P)-X\left(P^{N}\right) .
$$

The net revenue accruing to the government from the emission tax and tariff is thus equal to $r(t, \tau)$ $=\tau p^{*} M\left(P^{N}\right)+t \theta X\left(P^{N}\right)$, and is assumed distributed equally across consumers. ${ }^{10}$

Since rewards to the owners of the sector-specific factor depend on the trade policy and the pollution tax, they have an incentive to lobby the government for more favorable policies. But, since the trade policy is assumed exogenously determined in multilateral negotiations, lobbying is focused only on the pollution tax rate. Thus, factor owners, who are a small fraction of the population, are assumed able to form a lobby group that offers the government a prospective bribe. In contrast, the more numerous consumers confront sufficiently severe free-riding problems that preclude organization into an effective lobby group (see [44]). ${ }^{11}$

\subsection{The political equilibrium}

This section examines how bribery by the lobby affects the political equilibrium pollution tax. The timing of the game is as follows. In the first period, the producer lobby group offers the government a bribe schedule, $S(t)$, which is contingent on the environmental policy stance of the government. In the subsequent period, the government determines its optimal environmental policy, and collects the associated bribe. Finally, firms determine production and abatement levels taking the tariff and environmental policy as given. We solve the model by backward induction.

Since the organized producer lobby contains few individuals, it ignores consumer surplus and revenues (it receives a miniscule share), and thus has a utility function given by

$$
V(t, \tau) \equiv \pi\left(P^{N}\right)
$$

\footnotetext{
${ }^{9} A(t)$ is a concave function provided $\partial^{3} \theta / \partial A^{3}$ is sufficiently small, which is an assumption often invoked since the third derivative has no obvious economic interpretation [40].

${ }^{10}$ In case $r(t, \tau)<0$, a lump sum tax is collected from all consumers (the import and export-subsidy cases).

${ }^{11}$ This may be justified by assuming that pollution damage is so widely dispersed that it does not induce the affected individuals to form a lobby group. Baron [8] denotes this a particularist policy, where the benefits of a tax concession are concentrated, but the environmental costs are so thinly spread that they do not provide sufficient incentive for individuals to organize a lobby group, or make political donations.
} 
Following Grossman and Helpman [31], the government is assumed to maximize a weighted sum of the bribe received and aggregate gross-of-contributions social welfare equal to

$$
G(t, \tau)=S(t)+\alpha W(t, \tau),
$$

where $W(t, \tau)$ is aggregate social welfare and $\alpha>0$ is the weight given by the government to aggregate social welfare relative to the bribe. Following Fredriksson and Svensson [30], $\alpha$ represents the government's willingness to set policies that deviate from the welfare maximizing level in return for bribes, and therefore is a useful measure of the level of corruption (degree of corruptibility). This interpretation is similar to Schulze and Ursprung [50], who point out that in this type of model bribes are given in order to influence government policy, not the election outcome, and thus (p. 68) "the portrayed interaction between the organized interest groups and the government meets the circumstances of corruption." The level of corruption in the model is reflected by the government's willingness to allow lobby groups to influence the process of environmental policy formation, e.g., the propensity to sell policies for personal gains in the form of monetary transfers. This view of corruption is consistent with that of Bardhan [7], who defines corruption as "the use of public office for private gain" (p. 1321), and to Shleifer and Vishny [51, p. 599] who argue that corruption is "the sale by government officials of government property for personal gain", where government property refers to various policies affecting economic activity. ${ }^{12}$ Our formulation also resembles the government's objective function of López and Mitra [42]. In their model, the degree of corruptibility of the government is a weight between 0 and 1 on monetary payments relative to the probability of re-election.

Aggregate social welfare gross-of-contributions is given by the sum of factor rewards, labor income, consumer surplus from consumption, tariff and pollution tax revenues, minus the damage from pollution:

$$
W(t, \tau) \equiv \pi\left(P^{N}\right)+L+N C(P)+r(t, \tau)-\gamma N \theta X\left(P^{N}\right) .
$$

From the first order condition for (6), the welfare maximizing pollution tax is given by

$$
t^{w}=\gamma N+\frac{\tau p^{*} \theta\left(\partial X / \partial P^{N}\right)}{\theta^{2}\left(\partial X / \partial P^{N}\right)-X(\partial \theta / \partial A)(\partial A / \partial t)},
$$

where the second term is positive. Note that with $\tau>0$, the second-best tax rate $t^{w}$ is set above the marginal disutility from pollution, given by $\gamma N$, in order to correct the positive output effect. We assume that the second-order condition is satisfied, i.e., $\partial^{2} W(t, \tau) / \partial t^{2}<0$.

In the well-known model developed by Bernheim and Whinston [9] and Grossman and Helpman [31], the Nash equilibrium pollution tax, $t^{*}$, can be found using the following two necessary conditions:

$$
\begin{aligned}
t^{*} & =\underset{t}{\arg \max } S^{*}(t)+\alpha W(t, \tau) \text { on } \mathrm{T}, \\
t^{*} & =\underset{t}{\arg \max }\left[V(t, \tau)-S^{*}(t)\right]+\left[S^{*}(t)+\alpha W(t, \tau)\right] \text { on } \mathrm{T} .
\end{aligned}
$$

Condition $(\mathrm{C} 1)$ requires that the equilibrium policy, $t^{*}$, maximizes the government's utility function, while by $(\mathrm{C} 2)$ the tax also maximizes the joint utility of the lobby and the government.

\footnotetext{
${ }^{12}$ Rose-Ackerman [48] discusses seven different forms of high- and low-level corruption, one of which is the (legal or illegal) use of campaign contributions or bribes.
} 
The equilibrium characterization is found by taking the first-order conditions of (C1) and (C2), which yields

$$
\frac{\partial S\left(t^{*}\right)}{\partial t}+\alpha \frac{\partial W\left(t^{*}, \tau\right)}{\partial t}=0
$$

and

$$
\frac{\partial V\left(t^{*}, \tau\right)}{\partial t}-\frac{\partial S\left(t^{*}\right)}{\partial t}+\frac{\partial S^{*}\left(t^{*}\right)}{\partial t}+\alpha \frac{\partial W\left(t^{*}, \tau\right)}{\partial t}=0 .
$$

Substituting (8) into (9) yields

$$
\frac{\partial V\left(t^{*}, \tau\right)}{\partial t}=\frac{\partial S\left(t^{*}\right)}{\partial t}
$$

which reflects the local truthfulness of the bribe schedule. The characterization of the equilibrium pollution tax is found by substituting condition (10) into (8), which yields

$$
\frac{\partial G}{\partial t}=\frac{\partial V\left(t^{*}, \tau\right)}{\partial t}+\alpha \frac{\partial W\left(t^{*}, \tau\right)}{\partial t}=0
$$

In equilibrium, the government trades off profits (which determine the bribe) and social welfare at a rate of $\alpha$. Expanding terms in (11) (using (4) and (6)) yields

$$
\frac{\partial G(t, \tau)}{\partial t}=\underbrace{-\theta X}_{A}+\alpha \underbrace{\left[(t-\gamma N)\left(X \frac{\partial \theta}{\partial A} \frac{\partial A}{\partial t}-\theta^{2} \frac{\partial X}{\partial P^{N}}\right)+\tau p^{*} \theta \frac{\partial X}{\partial P^{N}}\right]}_{B}=0 .
$$

Note from (12) that the political equilibrium pollution tax must be lower than under welfare maximization. To see this, observe that term $A$ is negative, hence term $B$ must be positive which from (7) requires $t<t^{w}$ Note also that for sufficiently small $\tau, t<\gamma N$. In fact, with free trade or with an import subsidy $(\tau \leqslant 0), t<\gamma N<t^{w}$; with free trade, $t<\gamma N$ due solely to the effect of bribery. We make the following (plausible) assumption regarding the tax rate.

Assumption 1. The political equilibrium pollution tax rate is sufficiently small such that $t<\gamma N$.

This assumption implies that in the political equilibrium the tax rate is less than the marginal disutility of pollution. Our focus is thus on situations where the tax rate lies below the Pigouvian level. ${ }^{13}$ Note that from (12), $t<\gamma N$ is unambiguously true when $\tau<0$. Further differentiation of (12) yields the SOC of the equilibrium tax characterization (11), which is required to be negative for $\forall \alpha \in[0, \infty] .^{14}$

\footnotetext{
${ }^{13}$ This simplifying assumption is critical, as it avoids unambiguous theoretical predictions.

${ }^{14}$ The expression for the SOC is available from the authors upon request.
} 


\section{Predictions}

In this section, we explore the effects of corruption, environmental concerns, and trade liberalization on the politically determined pollution taxes, and in particular their interaction effects. We derive several predictions that form the basis of our empirical work. ${ }^{15}$

Prediction 1. In the political equilibrium, corruption reduces the pollution tax.

Proof. Totally differentiate (12) and rearrange:

$$
\frac{d t}{d \alpha}=-\frac{(t-\gamma N)\left(X \frac{\partial \theta}{\partial A} \frac{\partial A}{\partial t}-\theta^{2} \frac{\partial X}{\partial P^{N}}\right)+\tau p^{*} \theta \frac{\partial X}{\partial P^{N}}}{\frac{\partial^{2} G}{\partial t^{2}}}>0 .
$$

The sign follows from (i) the assumption that $\frac{\partial^{2} G}{\partial t^{2}}<0$, and (ii) from (12) we know that the numerator is positive $\left(t<t^{w}\right)$.

In this model, an increase in corruption implies that the government places a greater relative weight on bribes, and thus [by the local truthfulness condition (10)] on firm profits. The pollution tax consequently falls as corruption increases, deviating further from the welfare-maximizing tax rate.

Next, we explore the interaction between trade policy and corruption, and their joint effects on environmental policy. We define trade liberalization as a reduction in the exogenous trade policy instrument.

Prediction 2. Under Assumption 1, in the political equilibrium, trade liberalization:

(i) increases (decreases) the pollution tax in a protected sector if the level of corruption is high (low);

(ii) increases (decreases) the pollution tax in an anti-protected sector if the level of corruption is low (high).

Proof. Total differentiation of (12) yields

$$
\frac{d t}{d \tau}=\frac{d t}{d s}=\frac{\overbrace{\theta p^{*} \frac{\partial X}{\partial P^{N}}}^{A}-\alpha p^{*} \overbrace{\left[(t-\gamma N) \frac{\partial X \partial \theta \partial A}{\partial P^{N} \partial A \partial t}+\theta \frac{\partial X}{\partial P^{N}}\right]}^{B}}{\frac{\partial^{2} G}{\partial t^{2}}},
$$

where the denominator is negative by assumption. The sign of the numerator depends on the relative size of terms $A$ and $B$, which are positive under Assumption 1: (i) it follows that as

\footnotetext{
${ }^{15}$ An earlier version of this paper showed that these predictions generalize to the case of imperfect competition. Results are available upon request.
} 
corruption increases (decreases) (14) becomes negative (positive) since term $A(B)$ dominates. Hence, for sufficiently low (high) $\alpha$ trade liberalization in a protected sector always increases (decreases) the pollution tax. That is, $\operatorname{Lim}_{\alpha \rightarrow \infty} \frac{d t}{d \tau}=\frac{\theta p^{*} \frac{\partial X}{\partial P^{N}}}{\frac{\partial^{2} G}{\partial t^{2}}}<0$. And, (ii) since in an anti-protected sector the trade policy instrument has a negative sign $(\tau<0, s<0)$ trade liberalization implies an increase in the parameter value (a decrease in absolute value), and the sign of (14) is reversed in this case.

Consider a protected sector. Trade liberalization (a reduction of the import tariff or the export subsidy) has two main effects. On the one hand, trade liberalization reduces output in the polluting sector. As the marginal profits from bribery fall (since less is at stake when production declines), the bribe offer declines [reflected in the local truthfulness condition (10)]. Hence, the pollution tax rises through this channel (term $A$ ). Moreover, the second-best welfare motive for increasing the pollution tax declines (term $B$ ). This channel causes a reduction in the pollution tax. The degree of corruption determines the relative influence of terms $A$ and $B$ in (14). When the level of corruption is high (low), the effect of reduced bribery dominates (is dominated by) the effect of a reduced tariff distortion.

When bribery (corruption) has a strong impact on environmental policy, trade policy reform has a relatively large impact on the bribery effort. When the government is honest, on the other hand, welfare considerations may counter this upward pressure on the pollution tax. This upward force on the tax declines proportionally more as protection is dismantled when the government is honest. In sum, our theory identifies an interaction between trade policy and corruption.

Finally, we consider the effect of an increase in the share of consumers with environmental concerns.

Prediction 3. In the political equilibrium,

(i) an increase in the share of the consumers with environmental concerns raises the pollution tax, and

(ii) the effect disappears as corruption increases.

Proof. Totally differentiate (12) and rearrange:

$$
\frac{d t}{d \gamma}=\frac{\alpha N\left(X \frac{\partial \theta}{\partial A} \frac{\partial A}{\partial t}-\theta^{2} \frac{\partial X}{\partial P^{N}}\right)}{\frac{\partial^{2} G}{\partial t^{2}}}>0
$$

(i) The denominator and the numerator are unambiguously negative, and (ii) as $\alpha$ in (15) approaches zero, then $\frac{d t}{d \gamma} \rightarrow 0$.

The greater the share of the population suffering disutility from pollution, the greater the equilibrium pollution tax. However, this effect on disutility from pollution only translates into policy changes to the extent that welfare matters to the government. If environmental quality is a 
normal good then increases in income will, ceteris paribus, raise environmental awareness. Hence, in the empirical work below, we interpret an increase in income as an increase in the share of the population having environmental concerns.

\section{Empirical model and data}

To test the main assertions of the theory, our empirical analysis proceeds by examining environmental stringency levels within and between countries. When significant discrepancies exist, we analyze whether openness of the economy or corruption levels might be responsible for the differences. Amongst other things, in the empirical analysis our goal is to provide insights into policy-based questions that remain largely unresolved: First, is trade liberalization correlated with the stringency of environmental regulations? Second, is there a statistical association between the level of corruption and the stringency of environmental regulations? Third, are there interaction effects between trade liberalization and corruption that are related to environmental standards? Fourth, does income interact with corruption in its effect on environmental policy determination?

Using country level data from 1982 to 1992, we implement the random effects regression model due to Balestra and Nerlove [6]:

$$
E n v_{i t}=\beta^{\prime} J+\omega_{i t}
$$

where $\operatorname{Env}_{i t}$ represents the environmental stringency measure for country $i$ time period $t$; $J$ is our independent variable vector described below, $\omega_{i t}=u_{t}+\alpha_{i}+e_{i t} ; E\left[\alpha_{i}\right]=0, E\left[u_{t}\right]=0, E\left[\alpha_{i}^{2}\right]=\sigma_{\alpha}^{2}$, $E\left[u_{t}^{2}\right]=\sigma_{u}^{2}, E\left[\alpha_{i} \alpha_{j}\right]=0$ for $i \neq j, E\left[u_{t} \alpha_{z}\right]=0$ for $t \neq z$, and $u_{t}, \alpha_{i}, e_{i t}$, are orthogonal for all $i$ and $t$. By construction, the random effects $\alpha_{i}$ capture important heterogeneity across countries that would be left uncontrolled in a standard cross-sectional model. In addition, the time effects $u_{t}$ capture any factors that are dynamic but affect the level of environmental stringency, such as global preference changes due to education and technology.

A few features of (16) warrant further discussion. First, finding a dynamic measure of environmental stringency to test our hypotheses is a difficult task. We restricted our search over environmental measures that have both within-country and between-country variation so we could control for important unobservable factors that may influence the level of stringency. Our choices were severely limited, as most environmental regulatory indices at the country level are cross-sectional estimates based on 1 year of data. In the end, we chose a measure based on the consumption of goods. Our consumptive proxy for the level of environmental stringency is grams of lead content per gallon of gasoline. For our purposes, such data are available annually from 1982 to 1992 for 48 countries. ${ }^{16}$ Given that lead emissions are precursors to harmful local air

\footnotetext{
${ }^{16}$ We follow [22,38] in focusing on the 48 countries with 1990 populations over 10 million and for which data were continuously reported. This procedure is followed to limit misreporting and inconsistencies. Yet, this approach presents a potential sample selection problem. To address this concern, we randomly selected another group of 48 countries and used a Probit model to obtain insights into the issue. We regressed whether the country had data available ( 1 if yes, 0 if no) on observable characteristics included in the Penn World Tables (e.g., per capita income, population). We find that population is significant at marginal significance levels, which makes sense given our selection criteria. Accordingly, we should note that our findings are a representative description for the population conforming to our selection criteria, yet inference beyond this particular population is risky.
} 
pollutants, a country with relatively strict environmental policy should allow lower lead content per gallon of gasoline. For example, in 1982 Germany had a lead content measure of $0.52 \mathrm{~g}$ per gallon of gasoline, whereas Chile had a lead content of $3.12 \mathrm{~g}$ per gallon of gasoline. During our sample period, the average country had approximately $1.78 \mathrm{~g}$ of lead per gallon of gasoline. Lead content in gasoline has been used by previous authors to measure regulatory stringency for other purposes (e.g, [22,38]), and to our knowledge represents the most viable dynamic consumptive proxy for environmental stringency at the country level. For a nice description of the lead data, which comes from Octel's Worldwide Gasoline Survey, see [38].

Given that we believe our consumptive-based measure is a signal of environmental stringency, it is necessary to provide support for this claim. Several alternative methods exist to measure international differences in environmental compliance costs. To accomplish our goal, we examine two geographically narrow measures and one broader measure. To conserve space, we direct the reader to the appendix, where we provide a thorough description of our three alternative measures. Computing simple correlations between these three alternative measures and our lead index provides evidence consistent with our conjecture. First, we find a computed correlation coefficient of -0.78 between the two broad indices (lead and the DAS index), suggesting that the indices are highly correlated in the correct direction: greater DAS figures are associated with lower levels of lead in gasoline. Second, our two narrow environmental stringency variables are also correlated with the lead measure: R\&D and lead $(r=-0.38)$ and membership in environmental organizations and lead $(r=-0.45)$. These correlations suggest a degree of consistency throughout our various proxies.

A second feature of (16) that warrants further discussion is that the data used to estimate (16) do not form a balanced panel. We therefore use unbalanced panel data estimation techniques. In particular, the diagonal blocks in the covariance matrix are of different sizes, which induces group-wise heteroscedasticity. Our estimation procedure adjusts for this problem, as we present feasible GLS estimates. Third, we include an overall constant in variable vector $J$, but the restriction $\sum \alpha_{i}=\sum u_{t}$ avoids violation of the rank condition. Fourth, we model $\alpha_{i}$ and $u_{t}$ as random country and time effects, which treats unmeasured characteristics as error components, economizes on degrees of freedom, and yields coefficients that are not conditioned on unmeasured effects.

Fifth, regressors included in $J$ represent dynamic and static factors that are posited to influence the level of stringency of environmental standards. The first regressor of primary interest to the basic hypotheses is a trade openness measure. Given that openness of an economy is difficult to quantify, we follow [47] and examine several alternative measures. ${ }^{17}$ Our first openness measure is the basic measure of trade openness reported in standard international statistics, the share of exports and imports in GDP (Trade). These data are available in the Penn World Table (PWT)

\footnotetext{
${ }^{17}$ Following the received literature, we treat trade openness as exogenous. Even economies in our sample that can be considered large are constrained in their trade policy agenda. For example, as a member of the European Union (EU), Germany is not free to set trade policy: any external trade policy changes must first be negotiated within the EU, then with EU's negotiation partners (even if the EU would be able to set trade policy unilaterally, Germany's influence would be hampered by the other members' agendas). Prior to EU formation, the Treaty of Rome (1957), which included Germany, created a customs union, where import duties were removed internally, and the external barriers were unified in stages between 1958 and 1968. Yet, we should be clear that this is a fruitful area for future empirical research since trade openness could very well be modeled endogenously.
} 
version 5.6 or the World Bank's "World Development Indicators." The second measure of openness is the value of taxes on international trade and transactions as a percentage of total trade values (Taxes). These taxes cover items such as import and export duties, foreign exchange taxes, and profits on import or export monopolies. The final two measures are duties on imports (Import Duties) and exports (Export Duties). These regressors represent the value of import (export) duties as a percentage of total import (export) value. The final three measures are from the IMF's "Government Finance Statistics."

Our measure of governmental honesty is the index constructed by the International Country Risk Guide (Govt. Honesty). The governmental honesty variable is a corruption measure that represents an indication of the likelihood that "high government officials are likely to demand special payments". In addition, the data are meant to capture whether "illegal payments are generally expected throughout lower levels of government" in the form of "bribes connected with import and export licenses, exchange controls, tax assessment, policy protection, or loans" $[39$, p. 225]. The index is directly related to governmental honesty and ranges from 0 to 6 , with 0 being the least honest and 6 being the most honest. In this index, countries such as Egypt and Ghana have Govt. Honesty values of 1 in 1982, whereas Austria and Australia have honesty values of $6 .^{18}$

Two results emerging from our theory is the prediction that (i) the effect of trade openness is conditional on the degree of corruption and that (ii) responses to increases in the demand for environmental quality depend on the level of corruption. We therefore include two interaction terms in vector $J$ to test for these interaction effects: Govt. Honesty ${ }^{*}$ Openness to examine the first conjecture and Govt. Honesty ${ }^{*}$ GDP to test the second hypothesis.

We also include various control variables in $J$ to reduce the unexplained variation in the regressand. Given that some studies find a nonlinear relationship between a measure of output (or incomes) and environmental quality (see, e.g., [37]), we include real GDP per capita and higher order GDP per capita terms in $J\left(G D P ; G D P^{2} ; G D P^{3}\right)$. Other regressors in $J$ include a dichotomous variable that indicates whether the country is developed or undeveloped (Developed); where Developed $=1$ if the country is a developed nation, 0 otherwise: ${ }^{19}$ This particular regressor provides a control for the overall level difference in environmental policies across developed and developing countries. We control for the proportion of the population exposed to industrial pollution (marginal damage) by including urban population as a percentage of total population (\%Urban). And, finally, to control for the general structure of the work force and its ability to produce political pressure, we include the percentage of labor force in industry ( $\% L F I)$ (see [44]). Both the urban population variable and the labor force variable are from the World Bank's World Development Report. Table 2 provides summary statistics.

\footnotetext{
${ }^{18}$ To provide a robustness test, we obtained alternative corruption measures from Shang-Jin Wei. These alternative measures are correlated with our measure, hence we suppress further discussion of these alternative measures.

${ }^{19}$ Countries included in the developing country group are Argentina, Brazil, Chile, China, Colombia, Egypt, India, Jamaica, Korea, Mexico, Philippines, Uruguay, and Venezuela. The remaining countries are considered developed.
} 
Table 2

Descriptive statistics

\begin{tabular}{|c|c|c|c|c|}
\hline Variable & Mean & $\begin{array}{l}\text { Standard } \\
\text { deviation }\end{array}$ & Minimum & Maximum \\
\hline Grams of lead per gallon of gasoline & 1.78 & 0.98 & 0.00 & 3.98 \\
\hline$G D P$ & 6795 & 5828 & 290 & 21,631 \\
\hline Developed & 0.40 & 0.49 & 0.00 & 1.00 \\
\hline$\%$ Urban & 55.6 & 24.3 & 9.00 & 97.00 \\
\hline$\% L F I$ & 32.1 & 9.8 & 3.00 & 60.00 \\
\hline Govt. Honesty & 2.57 & 1.57 & 0.00 & 6.00 \\
\hline \multicolumn{5}{|l|}{ Openness measures } \\
\hline Trade & 48.97 & 28.06 & 6.32 & 156.00 \\
\hline Taxes & 0.04 & 0.07 & 0.00 & 0.37 \\
\hline Import Duties & 0.06 & 0.10 & 0.00 & 0.64 \\
\hline Export Duties & 0.01 & 0.04 & 0.00 & 0.34 \\
\hline
\end{tabular}

\section{Empirical results}

Empirical results from estimation of (16) are presented in Table 3. Columns 1-4 of Table 3 contain estimates from the regression model based on which openness measure was included. For example, column 1 regression estimates are for the model that uses Trade as the openness measure. When considering our results, it is important to note that likelihood-ratio tests suggest that all model types are significant at the $p<0.05$ level. This finding implies that our errorcomponents model explains a significant portion of the variation in the regressand. In addition, LM statistics indicate that, in every model, the null hypothesis of homogeneity of unmeasured country- and time-specific effects is rejected at the $p<0.05$ level. ${ }^{20}$

Broadly speaking, the empirical results in Table 3 provide coefficient estimates that support the theory. ${ }^{21}$ In the Trade model, we see that the share of exports and imports as a proportion of GDP is associated with decreases in gasoline lead content, signaling an increase in environmental protection. This finding implies that a more open economy will tend to have more stringent environmental standards. In the other three models, positive and significant coefficient estimates imply that increases in Taxes, Import Duties, and Export Duties are associated with increases in the level of allowable lead content per gallon of gasoline. This finding suggests again that as an economy becomes more open, it tends to have more stringent environmental standards. ${ }^{22}$ To

\footnotetext{
${ }^{20}$ We should note however that for the latter three model types we did not find a positive estimated component for the variance of $u_{t}$. Nonetheless, in the first model type inclusion of time effects does not significantly alter the findings so we are comfortable presenting the one-way random effects estimates.

${ }^{21}$ Since Govt. Honesty and some of our openness measures are correlated to a degree, we also experimented with regression models that included each of the important variables (Govt. Honesty and trade openness) separately. Our results are robust to these changes in specification.

${ }^{22}$ Hilton and Levinson [38] point out that in some countries the average lead content increased as income rose because consumers substituted to higher octane gasoline, with more lead, as their incomes expanded. This would suggest that as an economy opens, and incomes increase, lead content also increases. This effect would tend to preclude the data from matching our theoretical predictions.
} 
Table 3

Panel data regression estimates

\begin{tabular}{lcccc}
\hline & \multicolumn{3}{c}{ Model type } \\
\cline { 2 - 5 } & Trade & Taxes & Import Duties & Export Duties \\
\hline Openness & $-0.02^{* *}$ & $8.62^{* *}$ & $4.3^{* *}$ & $11.9^{* *}$ \\
Govt. Honesty & $(2.6)$ & $(3.4)$ & $(5.3)$ & $(3.3)$ \\
& -0.14 & -0.17 & $-0.18^{* *}$ & $-0.46^{* *}$ \\
Govt. Honesty & $(1.6)$ & $(1.2)$ & $(2.4)$ & $(3.6)$ \\
Openness & $0.003^{* *}$ & $-1.97^{* *}$ & $-0.62^{* *}$ & $\left(2.37^{* *}\right.$ \\
GDP & $(2.1)$ & $(2.3)$ & $(2.7)$ & $-0.1 \mathrm{E}-2^{* *}$ \\
& $-0.7 \mathrm{E}-3^{* *}$ & $-0.6 \mathrm{E}-3^{* *}$ & $-0.5 \mathrm{E}-3^{* *}$ & $(4.3)$ \\
GDP & $(5.0)$ & $(3.3)$ & $(5.7)$ & $0.7 \mathrm{E}-7^{* *}$ \\
& $0.4 \mathrm{E}-7^{* *}$ & $0.3 \mathrm{E}-7^{*}$ & $0.3 \mathrm{E}-7^{* *}$ & $(3.2)$ \\
GDP & $(3.3)$ & $(1.8)$ & $(3.9)$ & $-0.2 \mathrm{E}-11^{* *}$ \\
& $-0.1 \mathrm{E}-11^{* *}$ & $-0.6 \mathrm{E}-12$ & $-0.7 \mathrm{E}-12^{* *}$ & $(3.4)$ \\
GDP Govt. & $(2.4)$ & $(1.5)$ & $(3.6)$ & $0.6 \mathrm{E}-4^{* *}$ \\
Honesty & $-0.1 \mathrm{E}-4$ & $0.1 \mathrm{E}-4$ & $0.1 \mathrm{E}-4$ & $(2.3)$ \\
Developed & $(0.77)$ & $(0.70)$ & $(1.2)$ & $1.33^{* *}$ \\
& $1.08^{* *}$ & $1.03^{* *}$ & $0.93^{* *}$ & $(2.5)$ \\
\%Urban & $(2.8)$ & $(2.5)$ & $(2.3)$ & 0.02 \\
& $0.02^{* *}$ & 0.02 & $-0.02^{* *}$ & $(1.4)$ \\
\%LFI & $(2.8)$ & $(1.4)$ & $0.01^{* *}$ & - \\
& $0.02^{* *}$ & 0.007 & $(3.8)$ & 96 \\
$N$ & $(3.2)$ & 185 & 151 &
\end{tabular}

Notes: 1. Dependent variable is grams of lead per gallon of gasoline. 2. Model type is based on which openness measure is used in the regression. 3. Absolute value of $t$-statistics in parentheses beneath coefficient estimates. ${ }^{* *}\left({ }^{*}\right)$ denotes significant at the $p<0.05(0.10)$ level. All models are significant at the $p<0.01$ level.

provide a sense of the economic significance of the openness coefficient estimates, we consider the parameter estimate in the Import Duties specification measured at the sample means - olead/ dimport duties $=2.71=4.30-0.62(2.57) .{ }^{23}$ This estimate suggests that as the value of import duties as a percentage of total import value increases by one standard deviation (about 0.10 ), the level of allowable lead content per gallon of gasoline increases by $0.271 \mathrm{~g}$. In 1982 , this change in allowable lead content in gasoline would have represented an approximate movement from Belgian standards to Bangladeshi standards.

Concerning the effects of governmental honesty on environmental regulations, we find that a higher level of honesty tends to be associated with lower levels of allowable lead content per gallon of gasoline. Given that the Govt. Honesty index is inversely related to corruption levels, this result suggests that more corrupt countries tend to have less stringent pollution control policies. The magnitude of the effects are relatively stable across model type-for example, a one unit increase in the government honesty index in the Taxes specification is associated with a

\footnotetext{
${ }^{23}$ In this case the total effect of import duties on the regressand is the summation of its direct effect, 4.30, and its interaction effect, $-0.62^{*}$ (Govt. Honesty). Thus, the total effect depends on the level of Govt. Honesty. We use variable means when interpreting interaction terms.
} 
$0.25(-0.17-1.97(0.04)) \mathrm{g}$ decrease in the lead content of gasoline. In practice, government honesty has a standard deviation of 1.57 , hence a one unit increase in the corruption index represents a little more than one-half of one standard deviation.

We also find that, consistent with our theory, there are important interaction effects between corruption and openness: the interaction term Govt. Honesty ${ }^{*}$ Openness is significant in every specification at the $p<0.05$ level. Inference from the interaction terms is as follows. In the Import Duties model, the coefficient of Govt. Honesty ${ }^{*}$ Openness is negative, implying the effect of Import Duties on lead content in gasoline decreases as the value of the government honesty index increases (i.e. corruption falls). Or, likewise, as a country becomes more corrupt, the "strictness-raising" impact of trade liberalization on environmental regulations increases. In fact, consistent with Prediction 2, the effect of trade openness on environmental policy depends crucially on the degree of corruption. For example, in the Taxes model, a unit increase in trade openness reduces lead content in countries at the mean of Govt. Honesty by dead/Otaxes $=3.56=(8.62-1.97(2.57)) \mathrm{g}$ of lead. However, a similar increase in trade openness in countries with Govt. Honesty 1.5 standard deviations above the mean leads to an increase in lead content by $1.08=[8.62-1.97(2.57+1.5(1.57))] \mathrm{g}$ of lead. Thus, except for a relatively small number of countries in our sample, trade liberalization is associated with lower lead content in gasoline. Governmental corruption therefore tends to amplify the positive effect of trade openness on the stringency of environmental regulations. As can be seen from the parameter estimates in the other three models, inference is similar across all specifications.

The interaction coefficient estimates also provide a sense of the effects of governmental corruption levels under different trade regimes. Consider again estimates from the Import Duties regression model. A negative coefficient of Govt. Honesty ${ }^{*}$ Openness suggests that changes in corruption levels have a greater absolute effect on environmental policy in relatively closed economies. The sign of the interaction effect is consistent across regression models and implies that distorted trade policies increase the influence of corruption on environmental policy. This result suggests that corruption and protection are complements in the creation of environmental policy distortions (i.e. weak environmental policy).

Other empirical estimates in Table 3 provide a few robust results across the four specifications. For example, the interaction variable Govt. Honest $y^{*} G D P$ is significant only in one of our models (Export Duties) at conventional levels, inconsistent with our theory. This finding suggests that our data do not provide strong evidence that responses to increases in the demand for environmental quality depend on the level of corruption. Lead content and real GDP per capita have a similar relationship to that found in other studies (see, e.g. [38]). In our case, the results suggest that as incomes rise, levels of lead in gasoline follow a sideways S-shape with the peak occurring insample, and with many countries in our sample currently on the inverted-U portion of the estimated curve. Another consistent set of coefficient estimates is that conditional on per capita income levels and the other regressors, developed nations have approximately 1 more gram of lead per gallon of gasoline than developing nations. This effect is consistently significant at the $p<0.05$ level and suggests that although richer nations appear to be more environmentally aware than poorer nations, conditionally they are being outperformed by the developing nation group. ${ }^{24}$

\footnotetext{
${ }^{24}$ This may be due to political pressures from car and truck owners in developed countries, where reliance on these vehicles for personal and goods transportation may be greater than in developing countries (of course, motor scooters are important sources of transport (and pollution) in many developing countries). Alternatively, it may show that
} 
Table 4

Sensitivity check of main empirical estimates ${ }^{\mathrm{a}, \mathrm{b}, \mathrm{c}}$

\begin{tabular}{|c|c|c|c|c|c|c|c|c|}
\hline \multirow[b]{3}{*}{ Variable } & \multicolumn{8}{|c|}{ Model } \\
\hline & \multicolumn{2}{|c|}{ Trade } & \multicolumn{2}{|c|}{ Taxes } & \multicolumn{2}{|c|}{ Import Duties } & \multicolumn{2}{|c|}{ Export Duties } \\
\hline & Fixed & Random & Fixed & Random & Fixed & Random & Fixed & Random \\
\hline \multirow[t]{2}{*}{ Openness } & $-0.02^{*}$ & $-0.01^{* *}$ & $11.34^{*}$ & $7.76^{*}$ & $5.26^{*}$ & 0.81 & $12.33^{*}$ & $12.5^{*}$ \\
\hline & $(2.2)$ & $(1.8)$ & $(3.5)$ & $(2.6)$ & $(2.0)$ & $(0.3)$ & $(2.4)$ & $(2.6)$ \\
\hline \multirow[t]{2}{*}{ Govt. Honesty } & -0.17 & $-0.16^{* *}$ & -0.04 & -0.14 & -0.08 & -0.23 & $-0.53^{*}$ & $-0.36^{*}$ \\
\hline & $(1.5)$ & $(1.7)$ & $(0.3)$ & $(0.88)$ & $(0.4)$ & $(1.2)$ & $(2.6)$ & $(2.2)$ \\
\hline Govt. Honesty* & $0.5 \mathrm{E}-2^{*}$ & $0.3 \mathrm{E}-2$ & $-2.88^{*}$ & $-2.01^{*}$ & -0.98 & -0.06 & $-3.88^{*}$ & $-3.43^{* *}$ \\
\hline Openness & $(2.1)$ & $(1.5)$ & $(2.8)$ & $(2.1)$ & $(1.3)$ & $(0.1)$ & $(2.1)$ & $(1.9)$ \\
\hline \multirow[t]{2}{*}{$G D P$} & $-0.8 \mathrm{E}-3^{*}$ & $-0.2 \mathrm{E}-3^{*}$ & $-0.6 \mathrm{E}-3^{*}$ & $-0.3 \mathrm{E}-3^{* *}$ & $-0.7 \mathrm{E}-3^{*}$ & $-0.4 \mathrm{E}-3^{*}$ & $-0.2 \mathrm{E}-2^{*}$ & $-0.7 \mathrm{E}-3^{*}$ \\
\hline & $(3.57)$ & $(2.1)$ & $(3.3)$ & $(1.9)$ & $(3.0)$ & $(2.0)$ & $(3.6)$ & $(2.9)$ \\
\hline \multirow[t]{2}{*}{$G D P^{2}$} & $0.5 \mathrm{E}-7^{*}$ & $0.8 \mathrm{E}-8$ & $0.3 \mathrm{E}-7^{*}$ & $0.8 \mathrm{E}-8$ & $0.4 \mathrm{E}-7^{*}$ & $0.1 \mathrm{E}-7$ & $0.1 \mathrm{E}-6^{*}$ & $0.5 \mathrm{E}-7^{*}$ \\
\hline & $(3.2)$ & $(0.6)$ & $(2.0)$ & $(0.5)$ & $(2.1)$ & $(0.8)$ & $(2.7)$ & $(2.0)$ \\
\hline \multirow[t]{2}{*}{$G D P^{3}$} & $-0.1 \mathrm{E}-11^{*}$ & $-0.2 \mathrm{E}-12$ & $-0.7 \mathrm{E}-12$ & $-0.2 \mathrm{E}-12$ & $-0.9 \mathrm{E}-12^{* *}$ & $-0.4 \mathrm{E}-12$ & $-0.3 \mathrm{E}-11^{*}$ & $-0.2 \mathrm{E}-11^{*}$ \\
\hline & $(2.4)$ & $(0.4)$ & $(1.6)$ & $(0.5)$ & $(1.7)$ & $(0.8)$ & $(2.6)$ & $(2.4)$ \\
\hline$G D P^{*}$ Govt. & $-0.2 \mathrm{E}-4$ & $0.4 \mathrm{E}-5$ & $0.4 \mathrm{E}-7^{*}$ & $0.2 \mathrm{E}-4$ & $0.1 \mathrm{E}-5$ & $0.2 \mathrm{E}-4$ & $0.9 \mathrm{E}-4^{*}$ & $0.5 \mathrm{E}-4$ \\
\hline Honesty & $(1.3)$ & $(0.3)$ & $(2.3)$ & $(1.0)$ & $(0.1)$ & $(1.1)$ & $(2.0)$ & $(1.6)$ \\
\hline$R^{2}$ & 0.70 & 0.25 & 0.78 & 0.23 & 0.74 & 0.13 & 0.63 & 0.14 \\
\hline$n$ & 331 & 331 & 209 & 209 & 175 & 175 & 106 & 106 \\
\hline
\end{tabular}

${ }^{\text {a }}$ Dependent variable is grams of lead per gallon of gasoline.

${ }^{\mathrm{b}}$ Model type is based on which openness measure is used in the regression.

${ }^{\mathrm{c}}$ Absolute value of $t$-ratios are beneath coefficient estimates.

* Significant at the $p<0.05$ level;

** significant at the $p<0.10$ level.

Other controls also provide some insights. In the Trade and Import Duties regressions, \% ${ }^{2} F I$ is positive and significant at the $p<0.01$ level. $^{25}$ The estimates suggest that higher lead concentrations in gasoline are associated with countries that have a larger percentage of their labor force in industry. Our measure of population exposed to pollution levels (\%Urban) generally performs sporadically. Although it gains significance in two of four models, it is positive and statistically significant in the Trade model, whereas it is negative and significant in the Import Duties model.

While these findings support several of the major conjectures of our theory, it is important to carry out sensitivity checks of our main findings. Yet, given that our main empirical model includes static (Developed) and nearly static regressors (\% Urban and \%LFI), standard specification tests, such as Hausman tests, are invalid since the rank condition is violated in the fixed effects model. We therefore provide Table 4, which includes fixed and random effects

\section{(footnote continued)}

developed nations are transferring their technology and education to developing countries, inducing a "greener" growth than their predecessors' growth [47,53].

${ }^{25}$ Note that $\%$ LFI is excluded from the Export Duties regression because its inclusion did not allow convergence of the estimation procedure. We are comforted with the fact that when it was included and convergence was achieved (by dropping other regressors) it was never significant and did not change the character of the regression results. 
estimates of an equation that is similar to our main model (in this case the static (Developed) and nearly static regressors (\% Urban and \%LFI) are excluded). ${ }^{26}$ Estimates in Table 4 support the general results in Table 3. For example, in both the fixed and random effects models we find that more open economies tend to have more stringent environmental policies. And, this effect is statistically significant at conventional levels in the majority of specifications. Furthermore, Govt. Honesty remains of the theoretically correct sign and considering both its individual and joint significance (interaction term), we find statistically significant effects in six of the eight model types. Other parameter estimates are largely consonant with estimates in Table 3 and suggest that as incomes rise, levels of lead in gasoline follow a sideways S-shape, and that there is no consistent evidence that responses to increases in the demand for environmental quality depend on the level of corruption.

\section{Conclusions}

Academic research in the area of trade and the environment may eventually lead to generalizations that convert theory and empirical evidence into optimal policy-making, but such a conversion requires that we understand the myriad of complex relationships that exist in an open economy. In this paper, we take a step in this direction by focusing on the interactions between trade liberalization, corruption, and environmental policy determination. We begin by developing a political economy model of the endogenous determination of environmental policy. Several testable propositions emerge. For example, we find that the effect of trade policy changes is conditional on the level of governmental corruption. The exact nature of this interaction depends on whether protectionism and corruption are complements or substitutes in the creation of environmental policy distortions. Moreover, less corruption is associated with an increase in the stringency of environmental policy. Finally, the effect of an increase in the demand for environmental policy is also conditional on the level of corruption.

We take our theoretical predictions to task by examining lead content in gasoline from a broad mix of developed and developing countries. We generally find support for the theoretical predictions. First, countries with more open trade regimes tend to have stricter environmental regulations (lower lead content) on average, and this result is robust to several alternative measures of trade openness and environmental stringency. However, the effect of trade liberalization on environmental regulations is found to be conditional on the level of corruption: the greater the level of corruption in government, ceteris paribus, the larger are the effects of openness to trade on environmental stringency. Some of our empirical results even indicate that in countries with the most honest governments, the effect of trade openness is reversed: trade openness is associated with less stringent regulations. Second, corruption weakens the stringency of environmental policies. Moreover, a reduction in corruption has a greater effect on environmental policy in relatively closed economies. In essence, distorted trade policies (corruption) increase the effect of a reduction of corruption (trade liberalization) on lead content in gasoline. Thus, protectionism and corruption appear to be complements in the creation

\footnotetext{
${ }^{26}$ Hausman tests were attempted but the matrix was non-invertible in each case. Hence, for conservative purposes we direct the reader to the fixed effects model if one were to choose a model of choice.
} 
of environmental policy distortions. Finally, we find no robust evidence that the effect of income (measuring the demand for environmental quality) is conditional on the level of corruption.

Several policy implications emerge. First, it could be argued that trade liberalization reduces distortions in environmental policy-making by inducing an increase in their stringency in all countries, apart from the ones with the most honest governments. Our results cast doubt that concerns about the effects of trade liberalization on the environmental policy stringency in countries with relatively low stringency of regulations are well-founded. Improvements in environmental protection (due to trade liberalization) appear particularly pronounced in countries where regulations are the most distorted; i.e. in the most corrupt countries. Only in a small share of countries where environmental policy is already highly stringent (due to the presence of honest governments) may an increase in trade openness result in somewhat less stringent regulations. Second, and perhaps less controversially, efforts to reduce corruption will benefit efficient environmental policy-making. This is, in particular, the case where the level of protection is high. Therefore, our analysis suggests that the positive effects on environmental policies from fighting corruption may be largest amongst heavily protected countries.

\section{Acknowledgments}

We sincerely thank the three helpful referees, Ed Barbier, Eric Bond, Richard Boylan, Brian Copeland, Angeliki Kourelis, Essie Maasoumi, Muthukumara Mani, Daniel Millimet, Valerie Reppelin-Hill, Jim Rauch, Kamal Saggi, Curtis Taylor, and Scott Taylor, for valuable advice, discussions and comments. Robert Deacon, Tim Jeppessen, Valerie Reppelin-Hill, and Jakob Svensson graciously provided some of the data used in our analysis. Wallapa Chupawa provided able research assistance. The usual disclaimers apply.

\section{Appendix A}

In this appendix we discuss our three alternative environmental policy measures. Our first measure is public environmental R\&D expenditures as a proportion of GDP (OECD, 1995). These data were constructed to proxy for a measure of the willingness to allocate resources to environmental protection. The data for the period 1982-1992 refer to government budget appropriations or outlays for $\mathrm{R} \& \mathrm{D}$ for the control and care of the environment, covering pollution related to air, water, soil and substrata, noise, solid waste, and radiation. The data refer both to the prevention of pollution and to the identification and treatment of pollution. The data are expressed in US dollars at 1991 prices (and purchasing power parities) and are available for all OECD countries.

Our second measure of regulatory stringency is per capita membership of environmental organizations. Eurobarometer conducts public opinion surveys twice a year. The surveys contain an identical set of questions put to representative samples (1000 persons) of the population in each Member State. Occasionally the respondents are asked about their membership of environmental 
organizations. ${ }^{27}$ Data for the period 1982-1992 are available for nine Member States (Belgium, Denmark, France, Germany, Greece, Ireland, Italy, The Netherlands, and the UK). Membership of environmental organizations is an indication of the population's preferences for environmental protection. It is, however, a very indirect measure of the stringency of environmental regulations and it has at least two shortcomings. First, it is implicitly assumed that environmental preferences expressed by membership of environmental organizations influence the level of environmental protection chosen by the public authorities. Second, membership of environmental organizations are also influenced by the political culture in the Member State. In some Member States there may be a tradition (for instance due to a high degree of corporatism) that citizens are members in organizations. These states could mistakenly be categorized as environmentally stringent states.

Our third proxy measure is taken from a much richer assortment of countries and represents a production-based proxy for the level of environmental stringency. The proxy is derived from an index originally developed by Dasgupta et al. [21] for 31 countries for the agricultural, industry, energy, and urban sectors. Eliste and Fredriksson [27] extended the index to include 62 countries. The index is based on country reports for the 1992 United Nations Conference on Environment and Development in Rio (UNCED (1992)) on existing environmental regulations. Each country report is based on survey questions and was prepared under well-defined UNCED guidelines, making a cross-country comparison possible (see [21]). The reports provide specific information about the state of the environmental regulatory framework, focusing on existing environmental policies, legislation, control mechanisms, and enforcement. Using the information gathered, Dasgupta [21] developed the index by assigning the answers on each of 25 questions (with four parts per question) a score from 0 to 2 . The questions varied considerably, ranging from issues of water pollution to biodiversity. The scores were summed to yield an index with a maximum tally of 200. Countries with relatively strict environmental policies have higher scores than those with lax policies. For example, in 1990 Germany had an index score of 182, while Chile had a score of 92 .

Given that the Dasgupta et al. index is only for 1 year (1990), we use forecasting techniques to construct a panel data set for 30 of our countries. To proceed, we model the environmental index accordingly:

$$
D A S_{i}=\beta^{`} Z+\omega_{i},
$$

where $D A S_{i}$ is the Dasgupta et al. index for $1990, Z$ includes conditioning observables that influence a country's environmental regulatory stringency and, in addition to our theory, mainly follow [27,35] - for example, variables in $Z$ include measures of governmental corruption levels,

\footnotetext{
${ }^{27}$ There are three different questions about membership of environmental organizations. (1) Are you a member, would you consider joining, or would you not join a nature protection association? (2) Which of the following groups do you belong to? Among mentioned groups are conservation of nature, environmentalist, and animal welfare groups. (3) There are a number of groups and movements seeking the support of the public. Can you tell me whether you are a member or might join, or would certainly not join the nature protection associations? The number of members are defined as those stating that they were a member (in case of questions (1) and (3)), or those naming an environmental group in which they were a member (in case of question (2)).
} 
real GDP, real GDP squared, percent of population living in urban areas, percent of labor force in industry, and overall population. We then pair the estimated $\beta$ from (A.1) with appropriate regressors for 1982-1992 to predict levels of environmental stringency.

\section{References}

[1] A. Ades, R. Di Tella, National champions and corruption: some unpleasant interventionist arithmetic, Econom. J. 107 (1997) 1023-1042.

[2] A. Ades, R. Di Tella, Rents, competition, and corruption, Amer. Econom. Rev. 89 (1999) $2-993$.

[3] A. Ades, E. Glaeser, Evidence on growth, increasing returns, and the extent of the market, Quart. J. Econom. 114 (1999) 1025-1045.

[4] T.S. Aidt, Political internalization of economic externalities and environmental policy, J. Public Econom. 69 (1998) $1-16$.

[5] W. Antweiler, B.R. Copeland, M.S. Taylor, Is free trade good for the environment?, Amer. Econom. Rev. 91 (2001) 877-908.

[6] P. Balestra, M. Nerlove, Pooling cross section and time series data in the estimation of a dynamic model: the demand for natural gas, Econometrica 34 (1966) 585-612.

[7] P. Bardhan, Corruption and development: a review of the issues, J. Econom. Literature 35 (1997) $1320-1346$.

[8] D.P. Baron, Electoral competition with informed and uninformed voters, Amer. Polit. Sci. Rev. 42 (1994) $221-237$.

[9] B.D. Bernheim, M.D. Whinston, Menu auctions, resource allocation, and economic influence, Quart. J. Econom. 101 (1986) 1-31.

[10] R. Bommer, G.G. Schulze, Environmental improvement with trade liberalization, European J. Polit. Economy 15 (1999) 639-661.

[11] S. Coate, S. Morris, Policy Persistence, Amer. Econom. Rev. 89 (1999) 1327-1336.

[12] D. Coates, Jobs versus wilderness areas: the role of campaign contributions, in: R.D. Congleton (Ed.), The Political Economy of Environmental Protection, University of Michigan Press, Ann Arbor, 1996.

[13] Commission for Environmental Cooperation (CEC), Assessing environmental effects of the North American Free Trade Agreement (NAFTA). An analytical framework (Phase II) and issue studies, Environment and Trade Series, CEC Secretariat, Montréal, 1999.

[14] P. Conconi, C. Perroni, Issue linkage and issue tie-in in multinational negotiations, J. Internat. Econom. 57 (2002) $423-447$.

[15] B.R. Copeland, Tariffs and quotas: retaliation and negotiation with two instruments of protection, J. Internat. Econom. 26 (1989) 179-188.

[16] B.R. Copeland, Strategic interaction among nations: negotiable and non-negotiable trade barriers, Canad. J. Econom. 23 (1990) 84-108.

[17] B.R. Copeland, International trade and the environment: policy reform in a polluted small open economy, J. Environ. Econom. Management 26 (1994) 44-65.

[18] B.R. Copeland, S.M. Taylor, Trade and transboundary pollution, Amer. Econom. Rev. 85 (1995) $716-737$.

[19] M.L. Cropper, W.L. Evans, S.J. Berardi, M.M. Ducla-Soares, P.R. Portney, The determinants of pesticide regulation: a statistical analysis of EPA decision making, J. Polit. Economy 100 (1992) 175-197.

[20] R. Damania, When the weak win: the role of investment in environmental lobbying, J. Environ. Econom. Management 42 (2001) 1-22.

[21] S. Dasgupta, A. Mody, S. Roy, D. Wheeler, Environmental regulation and development. Across-country empirical analysis, Policy Research Working Paper No. 1448, The World Bank, Washington, DC, 1995.

[22] R. Deacon, The political economy of environment-development relationships: a preliminary framework, Mimeo, University of California, Santa Barbara, 1999.

[23] J.M. Dean, Testing the impact of trade liberalization on the environment: theory and evidence, in: P.G. Fredriksson (Ed.), Trade, Global Policy, and the Environment, World Bank Discussion Paper \#402, The World Bank, Washington, DC, 1999. 
[24] D. Dollar, Outward-oriented developing economies really do grow more rapidly: evidence from 95 LDCs, 1976-1985, Econom. Dev. Cultural Change 40 (1992) 523-544.

[25] J. Ederington, International coordination of trade and domestic policies, Amer. Econom. Rev. 91 (2000) $1580-1593$.

[26] S. Edwards, Trade orientation, distortions, and growth in developing countries, J. Dev. Econom. 39 (1992) 31-57.

[27] P. Eliste, P.G. Fredriksson, Environmental regulations, transfers and trade: theory and evidence, J. Environ. Econom. Management 43 (2002) 234-250.

[28] P.G. Fredriksson, The political economy of trade liberalization and environmental policy, Southern Econom. J. 65 (1999) 513-525.

[29] P.G. Fredriksson, N. Gaston, The importance of trade for the ratification of the 1992 climate change convention, in: P.G. Fredriksson (Ed.), Trade, Global Policy, and the Environment, World Bank Discussion Paper \#402, The World Bank, Washington, DC, 1999.

[30] P.G. Fredriksson, J. Svensson, Political instability, corruption and policy formation: the case of environmental policy, J. Public Econom. (2002), forthcoming.

[31] G.M. Grossman, E. Helpman, Protection for sale, Amer. Econom. Rev. 84 (1994) 833-850.

[32] G.M. Grossman, A.B. Krueger, Environmental impacts of NAFTA, in: P. Garber (Ed.), The US-Mexico Free Trade Agreement, MIT Press, Cambridge, MA, 1993.

[33] A. Harrison, Openness and growth: a time series, cross-country analysis for developing countries, J. Dev. Econom. 48 (1996) 419-447.

[34] E. Helland, The enforcement of pollution control laws: inspections, violations, and self-reporting, Rev. Econom. Statist. 80 (1998) 141-153.

[35] J.V. Henderson, Effects of air quality regulation, Amer. Econom. Rev. 86 (1996) 789-813.

[36] H. Hettige, R.E.B. Lucas, D. Wheeler, The toxic intensity of industrial production: global patterns, trends and trade policy, Amer. Econom. Rev. 82 (1992) 478-481.

[37] A.L. Hillman, H.W. Ursprung, Greens, Supergreens and international trade policy: environmental concerns and protectionism, in: C. Carraro (Ed.), The International Dimension of Environmental Policy, Dordrecht, Kluwer, 1994.

[38] F. Hilton, A. Levinson, Factoring the environmental Kuznets curve: evidence from automotive lead emissions, J. Environ. Econom. Management 35 (1998) 126-141.

[39] S. Knack, P. Keefer, Institutions and economic performance: cross-country tests using alternative institutional measures, Econom. Polit. 7 (1995) 207-227.

[40] J. Laffont, J. Tirole, A Theory of Incentives in Procurement and Regulation, MIT Press, Cambridge, MA, 1999.

[41] M.P. Leidy, B.M. Hoekman, Cleaning Up while cleaning up? Pollution abatement, interest groups and contingent trade policies, Public Choice 78 (1994) 241-258.

[42] R. López, S. Mitra, Corruption, pollution and the Kuznets environment curve, J. Environ. Econom. Management 40 (2000) $137-150$.

[43] P. Mauro, Corruption and growth, Quart. J. Econom. 110 (1995) 681-712.

[44] M. Olson, The Logic of Collective Action, Harvard University Press, Cambridge, MA, 1965.

[45] B.P. Pashigian, Environmental regulation: whose self-interests are being protected?, Econom. Inquiry 23 (1985) 551-584.

[46] M. Rauscher, On ecological dumping, Oxford Econom. Papers 46 (1994) 822-840.

[47] V. Reppelin-Hill, Trade and environment: an empirical analysis of the technology effect in the steel industry, J. Environ. Econom. Management 38 (1999) 283-301.

[48] S. Rose-Ackerman, Corruption: A Study in Political Economy, Academic Press, Inc., New York, 1978.

[49] J. Schleich, Environmental quality with endogenous domestic and trade policies, European J. Polit. Economy 15 (1999) 53-71.

[50] G. Schulze, H. Ursprung, The political economy of international trade and the environment, in: G. Schulze, H. Ursprung (Eds.), International Environmental Economics: A Survey of the Issues, Oxford University Press, Oxford, 2001.

[51] A. Shleifer, R.W. Vishny, Corruption, Quart. J. Econom. 108 (1993) 599-617. 
[52] A. Strutt, K. Anderson, Will trade liberalization harm the environment? The case of Indonesia to 2020, in: P.G. Fredriksson (Ed.), Trade, Global Policy, and the Environment, World Bank Discussion Paper \#402, The World Bank, Washington, DC, 1999.

[53] D. Wheeler, P. Martin, Prices policies and the international diffusion of clean technology: the case of wood pulp production, in: P. Low (Ed.), International Trade and the Environment, World Bank Discussion Paper \#159, The World Bank, Washington, DC, 1992. 